\title{
Money Attitudes in Workforce of Karachi
}

\author{
Salma Mirza* \\ Dr. Nadeem A. Syed
}

\begin{abstract}
This research was carried out with 150 working people of Karachi in order to investigate their attitudes towards money. The questionnaire was given to respondents from different organizations. Both blue collar and white collar workers were included. The data were analyzed by using explanatory variables, including gender, age, marital status, education and income. Findings indicate that the populations' money attitudes were linked to selected demographics such as education, gender and income. Also findings support the previous researches on the topic which prove that money attitudes such as power and prestige are correlated with distrust and anxiety. The results of this study are applicable to human resource, finance and marketing professionals alike. This would enable professionals in these areas to target their activities better with a substantial reduction in costs.
\end{abstract}

Key Words: Money attitudes, demographics, work force, Karachi

\section{Introduction}

\subsection{Background of Study}

What is money? This term has diverse meanings. If we look at its functional meaning, then the simplest definition is 'money is anything that is widely used for making payments and accounting for debts and credits. Davies (2002), Begg (1994) and many other economists define money as: 'Money is a medium of exchange, a measure of value, a standard of deferred payments and a store of value.' Wikipedia puts this description entertainingly as 'Money is a matter of functions four, a medium, a measure, a standard, a store.' The ability of money to be used as a medium of exchange has been hailed as one of the biggest intellectual discoveries of all time and has been put second only to language. Just as without language, exchange of ideas is extremely limited; in the same way, exchange of goods and services would be hindered and limited without the use of money. According to Macesich (2000), the advent of money solved the problem of 'the dual coincidence of wants in barter'. It has made exchange possible across individuals, groups and countries by providing them a standard payment against goods and services.

But individual views about money vary from that of economists' views. The term money has multiple meanings. In the most basic meaning, it is the basis of all monetary transactions (as stated above) but its symbolic meanings range from highly positive ideals such as security, esteem, status, achievement (Orr, 2007) to highly repugnant ones .

*Salma Mirza is a lecturer at IBA, Karachi.

Dr. Nadeem A. Syed is a faculty member at FAST, Karachi. 
To explain money attitudes, different researchers have adopted different approaches. Some have explained it with the help of needs (Oleson, 2004), while others have used personal values to explain money attitudes (Burgess, 2005). Some explain it purely on the basis of demographic variables (Özgen and Bayoglu, 2005). This last approach seems to be the most basic approach to begin analyzing the money attitudes of a society and this is where this research analyzes the working class of urban Karachi in Pakistan. Hence, the proposed study tries to quantitatively measure the relationship between Money Attitude Scale (MAS) and different demographic variables by the methodology used in Oleson (2004) and Özgen and Bayoglu (2005).

\subsection{Research Problem}

The purpose of this paper is 'to determine the relationship between Money Attitudes and Demographic Variables in Working Class Urban Karachiites' Following are some of the caveats accompanying this problem definition:

- $\quad$ This study does not test the validity of MAS in Pakistan rather it presupposes the validity and applicability of this construct as proved with literature (Burgess, 2005; Oleson, 2004; Yamauchi and Templer, 1982; Bonsu, 2007) and goes onto study the relationship between the money attitudes and different demographics.

- $\quad$ Even though, the study, by virtue of its quantitative nature, renders conclusive generalizations on the problem definition, it does not attempt to develop a causal relationship.

\subsection{Research Objectives}

The objectives of this study are to:

- $\quad$ Analyze and evaluate the scales authored by various researchers to assess money attitudes in people of urban Pakistan.

- Apply the scale on the consumer and analyze them according to their respective income, age, gender, educational qualifications and professions.

\subsection{Significance of the Study}

For organizations, this study is significant for three functional areas: marketing, consumer behavior and human resources. Marketers can target specific segments based on their money attitudes and add another dimension to market segmentation, branding and brand positioning. Human resources can work to increase employee satisfaction by providing suitable incentives to their employees in organizations based on their expected money attitudes.

\subsection{Scope of the Study}

The sample size of the study is 150 . This sample size is small as compared to the urban 
working class of Karachi but time constraints did not allow this researcher to go beyond this number. The sample covers people working in private sector organizations of Karachi.

\subsection{Research Methodology}

To study money attitudes, Money Attitude Scale (MAS) as developed by Yamauchi and Templer (1982) was used as this scale has proved its validity and reliability over several studies in different cultures (Bonsu, 2007), (Burgess, 2005), (Oleson, 2004), (Yamauchi and Templer, 1982). The analysis includes applying the factor loads calculated by the authors on the findings and using the composite factors for further analysis. The research began with a comprehensive secondary data analysis to uncover various theories and scales available for research. Then after selecting a suitable scale with proven validity, it was used to gather data in a survey.

\subsection{Research Design}

Questionnaires were self-administered because some of the data were considered sensitive by the population as was apparent in the pretests. To keep interviewer biases in check, respondents were assured that individual data could not be tracked back to them. To reach out to assembly level workers, permission was obtained from the management of a local steel and pipe manufacturing plant and survey was conducted from their factory workers. For this purpose, the survey questionnaire was also translated into Urdu. For some white collar workers, questionnaires were also converted into electronic form and emailed to them but self-administration remained the dominant method of surveying.

The questionnaire had two parts. The first part dealt with money attitudes, i.e. the MAS scale. The second portion consisted of six questions to determine where the respondents lie on the demographic variables.

\subsection{Population}

The target population is the urban working class of Karachi ranging from lower to upper socio-economic classes. The population has been restricted to only urban Karachi because of limited time and money resources. However, populations belonging to diverse metropolitan areas appropriately encompass the characteristics of a much larger population and can be cautiously generalized to other areas of the country.

\subsection{Sample}

The sample size was of 150 respondents belonging to various organizations including banks, educational institutions, and other manufacturing houses. Around 30 of these were assembly line workers while the rest were white collar workers. 


\subsection{Sampling Technique}

In most of the literature reviewed for this paper, a non-probability and non-random convenience sampling has been deployed. Oleson (2004) in his work has used university student cohort for his survey. Convenience sampling has been used here too but since the population is considerably different, care has been taken to select respondents from organizations instead of students. Also, it has been found relevant to interview working people instead of students since people who earn are expected to have a better understanding as well as a more mature attitude towards money.

\subsection{Measurement Scale}

The measurement scales are different for different variables. The MAS is a five-point 34-item Likert scale. It has been treated as an interval scale by assigning codes of 5 (strongly agree) to 1 (strongly disagree). This scale differentiates the money attitudes into five categories: Power-Prestige (MASPP), Retention-Time (MASRT), Distrust (MASD), Quality (MASQ) and Anxiety (MASA). Each statement on the scale was assigned a load factor according to Yamauchi and Templer (1982). In this way, summated scores were calculated for each individual along the five money attitudes. These attitudes were rounded off into single digits so as to obtain just five whole numbered values for each individual. These individual values were then cross-tabulated with demographic variables. The demographic variables were all nominally divided in categories as given in table 1 .

\subsection{Statistical Tools}

The statistical analysis is done on SPSS. Initially a detailed analysis is done on the sample demographics with complete cross-tabulations and descriptive analysis. Overall test of significance is then conducted on the money attitudes. A correlation analysis is conducted amongst the various attitudes variables. Finally, each of the demographic variable is cross-compared with each of the money attitude scores. In addition to SPSS, MS Excel has been used to develop graphs and charts for visual representation of data.

\subsection{Variables}

There are ten variables altogether for this study. These variables, their scales and their values (codes) are given in the table below: 


\begin{tabular}{|c|c|c|}
\hline \multicolumn{2}{|c|}{ Variable } & Possible Values \\
\hline MASPP & Interval & 5 (Strongly Agree) to 1 (Strongly Disagree) \\
\hline MASRT & Interval & 5 (Strongly Agree) to 1 (Strongly Disagree) \\
\hline MASD & Interval & 5 (Strongly Agree) to 1 (Strongly Disagree) \\
\hline MASQ & Interval & 5 (Strongly Agree) to 1 (Strongly Disagree) \\
\hline MASA & Interval & 5 (Strongly Agree) to 1 (Strongly Disagree) \\
\hline Gender & Nominal & 0 (Females), 1(Males) \\
\hline Marital Status & Nominal & 1 (Single), 2 (Married), 3-6 (Other) \\
\hline Education & Nominal & 1 (Uneducated), 2 (Primary), \\
\hline monthly & Nominal & 3 (Secondary), 4 (Masters), 5 (PhD.) \\
\hline Household & & 1 ( Less than 5000), 2 (5000-25000), 3 \\
Income PKR & & $(25001-50000), 4(50001-100000)$, \\
\hline Age & Nominal & 1 (100001-150000), 6 (More than 150000) \\
\hline & & $(46-55), 5$ (55+) \\
\hline
\end{tabular}

Table-1: Variables for the Study

\subsection{Research Limitations}

There were some limitations of this research. Firstly, the sample size of 150 is small and generalization based on this sample should be made with caution. Also, the sampling technique applied was convenience sampling which resulted in some anomalies that cannot be attributed to the rest of the population. For instance, a huge majority of the sample was selected from white collar workers compared to blue collared workers, which cannot be generalized to the population. This and other such inconsistencies can be corrected by taking a bigger sample and with the application of probability sampling techniques. Karachi, even though a cosmopolitan city, is not representative of the country. Thus, the reader should not extend the analysis and conclusions beyond this population. Finally, time and resource constraints as mentioned above limited the data gathering process.

\subsection{Literature Review}

Money has been described by Begg (1994) as a medium through which people exchange goods and services. Besides this, it is a store of value, a unit of account and a means of payment. These definitions of money describe it in terms of how it is used or the meaning of money in the language of economics or finance. In these descriptions, the concept of money can be equated to cash or currency or even wealth (if you take into account the 'store of value' part of the definition). The economists' description of money contrasts deeply with the psychologists' view. The economists' description of money as a medium of exchange is deemed overly simplistic by psychologists (Orr, 2007) and is criticized for ignoring the symbolic meaning of money. 
According to Lau (1998), 'Money is a very emotion-laden subject in our society. It connotes diverse meanings, many of which are highly evaluative and moralistic in nature.' Although in terms of usage, the term 'money' has a set of stable definitions; its symbolic definitions are anything but stable. The meaning of money and the emotions it arouses varies across individuals, organizations, cultures and nations. To some people money is an item to be accumulated and amassed, to others it is a sign of prestige and power, yet some feel that money is the root cause of all evils in society.

Although this 'feature of modern living' is probably the most significant determinant of our behavior, there is not much work to be found on the symbolic connotations of money. This has been attributed to the fact that there are hardly any standard scales available to measure such diverse attitudes (Yamauchi and Templer, 1982). Also as Lau (1998) points out that the attitude towards money is an acquired thing based on our upbringing and value systems. Since value systems vary greatly across cultures and continents, it is natural that a scale that encompasses money attitude in one continent may not be that pertinent in another.

Although previous researches on this topic have been carried across a myriad of disciplines including economics, sociology and anthropology (Orr, 2007), it is most relevant to begin with the psychological angle on the topic.

\subsection{Meaning of Money in Psychology}

In most of the literature covering this topic, theorists have gone to the works of wellknown psychologists to uncover what money means to us. According to Sigmund Freud, money has an anal character. He equated money to feces. Freud theorized that the human fascination with money can be equated with fascination with excrement. Our attitudes towards money ranging from repugnance to admiration are similar to the way we react to feces (Yamauchi and Templer, 1982). Hence, there is a reason why we call somebody wealthy 'filthy rich'. Freud contends that our underlying negative and dark feelings about wealth are ingeniously modified by our psychological defense mechanisms, into something beautiful or glamorous (Coutu, 2003). Therefore, human beings are relentlessly drawn towards this fascinating thing not entirely facing our unconscious beliefs that it has dark associations.

Other theorists have attached different belief systems to money. According to Melanie Klien (Coutu, 2003), the acquisition of money is part of the human self-destructive instinct. Human inherent death drive fuels our greed, an insatiable desperation to acquire money. Adler (Orr, 2007) suggested that people want to amass wealth to overcome feelings of inferiority. Fenichel held that the drive to collect money is fed by the motivation to acquire power and 'recapture infantile feelings of omnipotence' (Yamauchi and Templer, 1982). Heinz Kohut's opinion is different from Freud and his contemporaries. According to him, human beings are basically good and it is the environment that makes him greedy and spoilt. This view is supported by Lau (1998) who concluded that it is not nature, but nurture that develops attitudes towards money. 


\subsection{Money Motivation in Maslow's Hierarchy}

Although Maslow's famed theory on human needs (1954) does not primarily focus on money attitudes, it can be used to predict money attitudes based on the need level s/he is at. Maslow postulated that people are perpetually driven by one of the five needs that exist in hierarchical order. These five needs are physiological needs, safety and security needs, love and belonging needs, esteem needs and self-actualization needs. After fulfillment of a lower level need humans move on to the next need level. Therefore, if a person is at physiological need level, he would be motivated by money in order to fulfill his basic needs, whereas when at the level of self esteem, he would be motivated to acquire money to reflect his status and prestige. In a way, Maslow's theory has been able to reconcile the diverse views in the works of Freud, Adler, Klien, Jung and other psychoanalysts. Oleson, (2004) correlated the Need Theory and a money attitude scaled called the MAS, developed by Yamauchi and Templer (1982) and concluded that people's attitude towards money evolved as they moved from a lower need level to a higher one; i.e. as humans progressed on the hierarchy of needs, money became less and less important to them. Oleson aptly expresses this evolution in the paper titled 'Relationship between money attitudes and needs' as:

'Perhaps the maturation and higher levels of learning and thinking hypothesized by Maslow as being associated with the higher stages of needs are part of the reason for individuals being less interested in money during the latter stages of needs (i.e. esteem and self actualization).' (p. 91)

\subsection{Money Attitudes and Western Cultures}

Although many of the well-known theories in social psychology do not directly address the symbolic meaning of money, it is usually viewed in most literature as something that is gratifying and which signifies achievement, pleasure and a reward that everyone yearns for. Theorists found out that people perceived each other on how much they earned and thus, a highly paid person was perceived to be happy and a low paid person considered unhappy. This cultural attitude towards wealth accumulation came under a great deal of scrutiny after the dot com disasters and Enron scandal during the end of the 1990s.

Coutu (2003) has described the drive towards acquisition of money as an 'American disease'. In her very critical commentary on the mindsets in modern industrial nations, she points out that Americans in particular, and western societies in general, have adopted a new 'religion' in which accumulation of wealth is hardly a sin or 'root of all evil' (as written by St. Paul, the founder of Christian theology), instead it is virtue. She recalls the work of the German Sociologist Max Weber and states that in modern western societies (following the Protestant work ethics), worldly acquisitions and amassment of wealth has been taken as a 'sign of God's grace and approval'. Therefore, acquisition of money has been transformed into the American dream by virtue of which capitalist cultures are not ashamed to be greedy (Coutu, 2003). This view has been maintained by numerous social psychologists; most notable among them is Furnham (1996) in his 
book, 'The psychology of Money' as well as other subsequent writings. He states:

'Protestant work ethic and what limited empirical work there has been, suggests that Protestant work ethic beliefs are associated with security, collecting, miserliness and saving but also to autonomy and power. At the heart of the Protestant work ethic is an obsession with money as a sign of success and (grace) and hence a powerful indicator of Protestant work ethic beliefs.' (p.148)

The above commentary opens up the avenue of politico-religious belief systems in shaping our beliefs about money. But surprisingly, there is a glaring absence of this angle in almost all of the literature addressing symbolic meaning of money. Interestingly, the Holy Quran as well as the Bible takes a very moderate and practical stance on money. The Quran states that: 'And render to the kindred their due rights, as (also) to those in want, and to the wayfarer: But squander not (your wealth) in the manner of a spendthrift.' (Al-Isra, Chapter:17, Verse:26 ). Also another verse states that 'Wealth and sons are allurements of the life of this world: But the things that endure, good deeds, are best in the sight of thy Lord, as rewards, and best as (the foundation for) hopes'. (Al-Kahf, Chapter18, Verse: 46 ) These and other such verses conclude that money and wealth are to be used moderately and on good purposes. The Bible states: 'No one can serve two masters, for he will hate the one and love the other, or he will be devoted to the one and despise the other. You cannot serve God and Money.' (Mathew 6:24), displaying a rather negative stance towards hoarding of money. A conclusion from the above discourse can be reached that both religions (and indeed all other major world religions) prohibit their followers from excessive obsessive attitudes towards money.

\subsection{Measurement of Money Attitudes}

Beliefs towards money are translated in a variety of attitudes. Some of us symbolize money as something to be 'displayed'; others view money as something that provides a secure future. Each of these beliefs would be demonstrated in different behaviors, ranging from copious consumption on the one end of the continuum to miserly stinginess on the other. Hence, there would be a definite attitudinal difference about money between people who purchase expensive cars, homes and luxury goods, and those who buy modest cars and homes and utilitarian goods (Orr, 2007).

In a study conducted by Lau (1998), it was shown that money attitudes are generally acquired. These attitudes depend on a person's experience, professional role and value system. He observed that young children (who lack experience and professional roles and much grounding of any value system) do not have similar emotional reactions to money as older people had. 'To children money is primarily functional.' Adults, on the other hand, had distinct and varied emotional reactions to the word money. The results showed that business people viewed money as honest and better compared to school teachers. Also those people who viewed enjoyment, security and personal achievement to be more important viewed money to be more important. On the other hand, those 
who were more mature and pro-social found money to be less important (Lau, 1998). This finding is supported by a similar conclusion reached by Sjoberg (2006). Their research concludes that people who are high on emotional intelligence (EI) scale are less money oriented and those who are low on (EI) are more money-oriented.

\subsection{Scales to Measure Money Attitudes}

There have been many attempts to develop a uniform scale to measure money attitudes. In their work 'Toward a cross-disciplinary dialogue about the meaning of money', Yuon and Doyle (1999) have compared the personality types and dimensions as promulgated by various psychoanalysts with financial attitudes and behaviors. In this way, they have come up with four types of personalities each varying in the way they view money. The four personalities have been named; Amiable, Expressive, Analytic and Driver. Amiables have been found to be psychologically tender minded and introverted and who view money as not very important. Drivers are the opposite of Amiables, who are extroverted and tough-minded and who feel that they do not feel independent or free unless they have a good amount of money with them and their goal is to amass as much money as they could. Expressives consisted of people who were both tenderminded, extroverted and viewed money as important, but their chief goal in life was not amassing money. Analytics were introverted and tough-minded who said that money was not important for feeling independent or free but their chief goal was amassing wealth (Yuon and Doyle, 1999).

The most frequently used scale to measure money attitudes is one developed by Yamauchi and Templer in 1982. In their paper titled, 'The Development of a Money Attitude Scale', they have developed MAS in an attempt to quantify money attitudes on five aspects 'Power-Prestige' is an attitude to influence other people. 'Time-Retention' is a sign of budgeting and preparing for the future. 'Distrust' describes a person who has suspicious attitudes towards money. 'Quality' describes a person who focuses more on quality and less on cost associated with it, and 'Anxiety' describes a person who is always worried about money.

The details of this scale as described by Yamauchi and Templer are as follows:

- $\quad$ Power-Prestige: This factor pointed to the use of money to impress and influence others and as a symbol of success. A person who scores high on Power-Prestige seems to hold attitudes that indicate the importance of status seeking, competition, external recognition and acquisition. A low scorer, by contrast, appears to possess attitudes that minimize the concern for money as a symbol of success and status and as an instrument to influence others.

- $\quad$ Time-Retention: This factor describes behaviors aimed at the future which require painful preparation. Persons scoring high on this factor could be described as placing great value on the process of preparation as well as the goal of security in the future. Their motto may be thought of as 'be prepared'. The attitudes of low scorers on the other hand, could be described as reflecting a present rather than future-orientation with little concern for careful accounting of their funds. 
- Distrust: A high scoring person on Distrust would appear to maintain hesitant, suspicious and doubtful attitudes. By contrast, a low scorer is viewed as trusting and accepting of situations involving money.

- $\quad$ Quality: This factor pointed to the purchasing of quality products. Persons scoring high could be described as believing in getting the best or paying the most to get the quality desired. Low scorers are seen as holding the opposing attitude that quality is not important when purchasing products.

- Anxiety: A high scoring person on this factor could be viewed as holding the attitude that money is a source of anxiety as well as a source of protection from anxiety. Low scorers, conversely, could be described as less worrisome and less anxious with money and in money situations.

Burgess (2005) tested and verified the validity and reliability of MAS developed by Yamauchi and Templer (1982). Important findings related to MAS include; Anxiety is positively related with power and achievement and negatively related with benevolence and universalism; Distrust is positively related with power and achievement and negatively with self-direction and stimulation; Power/prestige is positively related to power and achievement and negatively related to benevolence, universalism, security and selfdirection; Quality is related positively to hedonism, stimulation and self-direction and negatively related with conformity and tradition; Retention/ time is related positively to tradition and conformity values, and negatively to hedonism, stimulation \& self-direction.

Rose and Orr (2007) further refined the scale by Yamauchi and Templer and developed a scale that measures and explores the symbolic meanings of money on the basis of four constructs; Status, Achievement, Worry and Security. Status is the tendency to perceive money as a sign of prestige and to impress people. Achievement is the tendency to perceive money as a symbol of one's accomplishments and sign of success. Worry is the tendency to be anxious excessively about money. And Security is defined as the tendency to save and value money for its ability to provide a sense of safety.

\subsection{Application of the MAS in Various Studies}

Engelberg and Sjoberg (2006) conducted a study to examine how money attitudes related with emotional intelligence by applying the Money Attitude Scale (MAS) and an Emotional Intelligence (EI) scale. According to this study, emotionally intelligent individuals valued money less as a sign of power, status, and prestige. Less money-oriented people were found to be more stable emotionally, geared toward achievement, and better able to withstand failure and deal efficiently with demanding challenges. As a result, low importance attached to money is linked to a high degree of life adjustment. Bonsu (2007) found that attitudes towards money are not very different between a developed and an emerging economy through focusing on Ghana's consumer culture. The study exploits the Yamunchi and Templer (1982) money attitude scale focusing on Power, Time, Distrust, Quality, and Anxiety.

Oleson (2004) links two theoretical constructs, i.e. Maslow's need hierarchy theory and Money attitudes finding a relationship between money and needs. The paper concludes 
that statistically, significant differences exist in genders regarding money attitudes, like obsession, power budget and achievement. Money attitudes were found to be mostly related to safety and esteem needs and least related to physiological, love and actualization needs.

Burgess (2005) tested and verified the validity and reliability of MAS developed by Yamauchi and Templer (1982). Important findings related to MAS include; Anxiety is positively related with power and achievement and negatively related with benevolence and universalism. Distrust is positively related with power and achievement and negatively with self-direction and stimulation. Power/prestige is positively related to power and achievement and negatively related to benevolence, universalism, security and self-direction. Quality is related positively to hedonism, stimulation and self-direction and negatively related with conformity and tradition. Retention/ time is related positively to tradition and conformity values, and negatively to hedonism, stimulation and self-direction.

Özgen and Bayoglu (2005), carried out their research with 300 Turkish college students in Ankara in order to investigate their attitudes to money. Their demographic variables were gender, age and family type. However, what differentiates their findings is that they compared students' past and future attitudes through demographic variables. Their results show that past and future money attitudes were related to gender and age demographic variables.

\subsection{Analysis and Findings}

\subsection{Demographic Analysis}

This section contains the demographic analysis of the sample. The overall demographic profile of the sample is given below:

\begin{tabular}{|c|c|c|}
\hline Category & Frequency & Percentage \\
\hline 1. Gender & & \\
\hline Males & 92 & $61 \%$ \\
\hline Females & 58 & $39 \%$ \\
\hline 2. Marital Status & & \\
\hline Single & 70 & $47 \%$ \\
\hline Married & 69 & $46 \%$ \\
\hline $\begin{array}{l}\text { Other (includes Engaged, } \\
\text { Divorced, Separated and Widowed) }\end{array}$ & 11 & $7 \%$ \\
\hline 3. Education & & \\
\hline Uneducated & 7 & $5 \%$ \\
\hline
\end{tabular}




\begin{tabular}{|c|c|c|}
\hline Primary & 2 & $1 \%$ \\
\hline Secondary & 13 & $9 \%$ \\
\hline Bachelors & 65 & $43 \%$ \\
\hline Masters & 60 & $40 \%$ \\
\hline $\mathrm{PhD}$ & 3 & $2 \%$ \\
\hline \multicolumn{3}{|c|}{$\begin{array}{l}\text { 4. Monthly Household } \\
\text { Income PKR }\end{array}$} \\
\hline Less than 5000 & 7 & $5 \%$ \\
\hline $5000-25000$ & 36 & $24 \%$ \\
\hline $25001-50000$ & 25 & $17 \%$ \\
\hline $50001-100000$ & 49 & $33 \%$ \\
\hline $100000-150000$ & 14 & $9 \%$ \\
\hline Greater than 150001 & 19 & $13 \%$ \\
\hline \multicolumn{3}{|l|}{ 5. Age } \\
\hline $16-25$ & 58 & $39 \%$ \\
\hline $26-35$ & 47 & $31 \%$ \\
\hline $36-45$ & 15 & $10 \%$ \\
\hline $46-55$ & 22 & $15 \%$ \\
\hline $55+$ & 8 & $5 \%$ \\
\hline \multicolumn{3}{|l|}{ 6. Profession } \\
\hline Factory worker & 27 & $18 \%$ \\
\hline Office worker & 123 & $82 \%$ \\
\hline
\end{tabular}

Table-2: Overall Demographic Analysis

The sample consisted of $61 \%$ male and $39 \%$ female respondents. Since this research was mainly carried out for working class Karachi dwellers, it is natural that the sample had a male bias. Furthermore, the sample contained $47 \%$ single and $46 \%$ married respondents. The rest (7\%) belonged to engaged, divorced and separated categories. These categories, due to their lack of significance, have been included in the 'other' category. In education, the biggest segments were of Bachelors and Master categories (43\% and $40 \%$ respectively). $9 \%$ had had Secondary education, $1 \%$ had primary education, $5 \%$ were uneducated and $2 \%$ were $\mathrm{PhDs}$. The fact that there were uneducated people in the sample as well underscores the fact that not everyone belonged to upper echelons and there were few who belonged to the lowest tiers as well. In monthly household incomes, $24 \%$ earned between Rs.5,000 to Rs. 25,000, $17 \%$ earned from Rs. 25,000 to Rs. $50,000,33 \%$ earned 50,000 to $100,000,9 \%$ earned from Rs. 100,000 to Rs. 150,000 and $13 \%$ earned above Rs. 150,000 . There were also $5 \%$ who earned less than Rs.5,000. In ages, 39\% were in $16-25$ category, 31\% in 26-35 
category, $10 \%$ were in $36-45$ category, $15 \%$ were in $46-55$ category and only $5 \%$ were 55 plus. This shows a distinct youth bias which can only be attributed to the fact that during the survey, younger people were more forthcoming in their responses and were easier to approach compared to older ones. In professions, there was a heavy bias towards office workers $(82 \%)$ as compared to factory workers $(18 \%)$.

\subsection{Analysis of Demographic Variables}

Among the females, there were about $45 \%$ who were single, $41 \%$ married and the rest were divided in 'other' categories. Among men, this composition was $48 \%$ single, $49 \%$ married and the rest were divided in 'other'. In comparing the data between gender and education, it is found that among the females, $41 \%$ were Bachelors and $45 \%$ were Masters. The rest were divided among 'other' categories. Similarly, the males were about $45 \%$ Bachelors, 37\% Masters and about 13\% Secondary educated. The rest were almost equally divided among 'other' categories.

When comparing gender with incomes, the overall composition shows that about $72 \%$ of the sample belongs to the Rs.5,000 to Rs. 100,000 range, about $5 \%$ belonged to the lowest tier and the rest were divided in higher income brackets. This shows an almost normally distributed sample with maybe a slight upper bias. Among females, the composition in Rs.5,000 to Rs. 25,0000 as well as the Rs. 25,000 to Rs. 50,000 ranges were identical at $21 \%, 24 \%$ belonged to Rs. 50,000 to Rs.100,000 range and about $31 \%$ belonged to Rs. 100,000 plus category. Among males the composition for Rs. 5000 to Rs. 25,000 was $26 \%$, Rs. 25,000 to Rs. 50,000 was $14 \%$, Rs. 50,000 to Rs. 100,000 was $38 \%$ and about $16 \%$ belonged to the higher than Rs.100,000 category.

About $70 \%$ of the sample belonged to 16 to 35 years bracket. Among the females, about $35 \%$ belonged to $16-25$ age bracket, $29 \%$ in 26 to 35 age category and $10 \%$ in 36 to 45 years of age group. Women belonging to 46 and above category were about $26 \%$. Among men, this composition had a heavier youth bias. About $41 \%$ belonged to the $16-25$ group, $33 \%$ to $26-35$ category, $10 \%$ to $36-45$ age category and about $16 \%$ were 46 or older. It can be concluded here that the sample generally had more young people than older ones and males were predominantly younger than their female counterparts.

The cross comparison between profession and education levels show that the sample had $80 \%$ respondents belonging to Bachelors and Masters Level. Among factory workers, the composition was tilted towards lower education with about $32 \%$ belonging to the uneducated class. These were low-paid assembly line workers who had had little or no formal education. But even in the factory workers, there were $33 \%$ and $30 \%$ belonging to Secondary and Bachelors levels. Among the office workers, around $90 \%$ of people were Bachelors or Masters. This leads us to the logical conclusion that office workers or white collar workers were better educated than blue collar workers, which matches with most data and literature on this topic. 


\begin{tabular}{|c|c|c|c|c|c|c|c|c|c|}
\hline & & & $\begin{array}{l}\text { Income } \\
\text { Less than } \\
5000\end{array}$ & $\begin{array}{l}5000- \\
25000\end{array}$ & $\begin{array}{l}25000- \\
50000\end{array}$ & $\begin{array}{l}50000- \\
100000\end{array}$ & $\begin{array}{l}100000- \\
150000\end{array}$ & $\begin{array}{c}\text { More } \\
\text { than } \\
150000\end{array}$ & Total \\
\hline \multirow[t]{6}{*}{$\begin{array}{l}\text { Profe- } \\
\text { ssion }\end{array}$} & $\begin{array}{l}\text { Fact- } \\
\text { ory }\end{array}$ & Count & 6 & 21 & & & & & 27 \\
\hline & & $\begin{array}{l}\% \text { within } \\
\text { profession }\end{array}$ & $22.2 \%$ & $77.8 \%$ & & & & & $100.0 \%$ \\
\hline & Office & Count & 1 & 15 & 25 & 49 & 14 & 19 & 123 \\
\hline & & $\begin{array}{l}\% \text { within } \\
\text { profession }\end{array}$ & $.8 \%$ & $12.2 \%$ & $20.3 \%$ & $39.8 \%$ & $11.4 \%$ & $15.4 \%$ & $100.0 \%$ \\
\hline & Total & Count & 7 & 36 & 25 & 49 & 14 & 19 & 150 \\
\hline & & $\begin{array}{l}\% \text { within } \\
\text { profession }\end{array}$ & $4.7 \%$ & $24.0 \%$ & $16.7 \%$ & $32.7 \%$ & $9.3 \%$ & $12.7 \%$ & $100.0 \%$ \\
\hline
\end{tabular}

Table-3: Cross tabulation between Profession and Income

The above table shows that the factory workers were paid lower (all belonging to less than Rs. 25,000 bracket) as compared to the white collar workers who were comparatively evenly divided across categories. Among the office workers, around $20 \%$ belonged to the Rs. 25,000 or lower bracket, around $60 \%$ to Rs. 25,000 to Rs. 100,000 bracket and about $26 \%$ to above Rs.100,000 bracket. This chart underscores the difference in income between blue collar workers and white collar workers.

\subsection{Descriptive Statistics on Money Attitudes}

\begin{tabular}{|l|c|c|c|c|c|}
\hline \multicolumn{2}{|c}{ N } & Minimum & Maximum & Mean & $\begin{array}{c}\text { Std. } \\
\text { Deviation }\end{array}$ \\
\hline $\begin{array}{l}\text { Power and } \\
\text { Prestige }\end{array}$ & 150 & 1.00 & 4.43 & 2.2916 & 0.8134 \\
\hline Retention Time & 150 & 1.00 & 5.00 & 3.4292 & 0.7123 \\
\hline Distrust & 150 & 1.25 & 5.00 & 2.9957 & 0.7992 \\
\hline Quality & 150 & 1.00 & 4.81 & 3.0342 & 0.7370 \\
\hline Anxiety & 150 & 1.00 & 5.00 & 3.0299 & 0.7726 \\
\hline Total & 150 & 8.11 & 22.63 & 14.7806 & 2.5148 \\
\hline Valid N (list wise) & 150 & & & & \\
\hline
\end{tabular}

Table-4: Descriptive Statistics

The above table shows descriptive statistics of various money attitudes in the sample. The highest average for any money attitude is of retention time and with a mean of 3.4. Quality and Anxiety attitudes were the same at 3.03. Distrust, and Power and Prestige scored at 2.9 and 2.3 respectively. This table shows that the sample belonging to urban 
working class of Karachi lays greater emphasis on monetary planning for the future but comparatively little emphasis on amassing wealth for status and power.

\subsection{Overall Test of Significance}

The tabulated results were analyzed through SPSS. First a t-test was carried out to see if each of the five money attitudes is significantly different from the neutral value. The table below shows that at 95\% Confidence Interval, Power-Prestige and Retention Attitude were significantly different from the neutral value. In other words, Pakistan's urban workforce has different attitude from neutral as far as Power Prestige and Retention is concerned. However, it is near neutral in case of Distrust, Quality, and Anxiety attitude.

\begin{tabular}{|c|c|c|c|c|c|c|}
\hline \multicolumn{7}{|c|}{ Test Value $=\mathbf{3}$} \\
\hline & \multirow[t]{2}{*}{$\mathbf{T}$} & \multirow[t]{2}{*}{ Df } & \multirow[t]{2}{*}{$\begin{array}{c}\text { Sig. } \\
\text { (2-tailed) }\end{array}$} & \multirow[t]{2}{*}{$\begin{array}{c}\text { Mean } \\
\text { Difference }\end{array}$} & \multicolumn{2}{|c|}{$\begin{array}{l}95 \% \text { Confidence } \\
\text { Interval of the } \\
\text { Difference }\end{array}$} \\
\hline & & & & & Lower & Upper \\
\hline MASPP & -10.669 & 149 & 0.000 & -0.70820 & -0.8394 & -0.5770 \\
\hline MASRT & 7.373 & 149 & 0.000 & 0.42887 & 0.3139 & 0.5438 \\
\hline MASD & -0.065 & 149 & 0.948 & -0.00427 & -0.1332 & 0.1247 \\
\hline MASQ & 0.561 & 149 & 0.575 & 0.03380 & -0.0852 & 0.1528 \\
\hline MASA & 0.476 & 149 & 0.634 & 0.03007 & -0.0946 & 0.1548 \\
\hline
\end{tabular}

Table - 5: Overall Test of Significance

\subsection{Correlation between Money Attitudes}

\begin{tabular}{|c|c|c|c|c|c|c|}
\hline & & $\begin{array}{c}\text { Power and } \\
\text { Prestige }\end{array}$ & $\begin{array}{c}\text { Retention } \\
\text { Time }\end{array}$ & Distrust & Quality & Anxiety \\
\hline \multirow[t]{3}{*}{$\begin{array}{l}\text { Power and } \\
\text { Prestige }\end{array}$} & $\begin{array}{l}\text { Pearson } \\
\text { Correlation }\end{array}$ & 1.000 & 0.125 & $0.541^{* *}$ & 0.191 & $0.618^{* *}$ \\
\hline & Sig. (2-tailed) & . & 0.128 & 0.000 & 0.019 & 0.000 \\
\hline & $\mathbf{N}$ & 150 & 150 & 150 & 150 & 150 \\
\hline \multirow[t]{3}{*}{$\begin{array}{l}\text { Retention } \\
\text { Time }\end{array}$} & $\begin{array}{c}\text { Pearson } \\
\text { Correlation } \\
\end{array}$ & 0.125 & 1.000 & $.393^{* *}$ & -0.023 & $0.298^{* *}$ \\
\hline & Sig. (2-tailed) & 0.128 & . & .000 & 0.776 & 0.000 \\
\hline & $\mathbf{N}$ & 150 & 150 & 150 & 150 & 150 \\
\hline \multirow[t]{3}{*}{ Distrust } & $\begin{array}{c}\text { Pearson } \\
\text { Correlation }\end{array}$ & $0.541^{* *}$ & $0.393^{* *}$ & 1.000 & -0.079 & $0.596^{* *}$ \\
\hline & Sig. (2-tailed) & 0.000 & 0.000 & . & 0.339 & 0.000 \\
\hline & $\mathrm{N}$ & 150 & 150 & 150 & 150 & 150 \\
\hline
\end{tabular}




\begin{tabular}{|c|c|c|c|c|c|c|}
\hline Quality & $\begin{array}{c}\text { Pearson } \\
\text { Correlation }\end{array}$ & 0.191 & -0.023 & -0.079 & 1.000 & 0.113 \\
\hline & Sig. (2-tailed) & 0.019 & 0.776 & 0.339 &. & 0.167 \\
\hline & $\mathrm{N}$ & 150 & 150 & 150 & 150 & 150 \\
\hline Anxiety & $\begin{array}{c}\text { Pearson } \\
\text { Correlation }\end{array}$ & $0.618^{* *}$ & $0.298^{* *}$ & $0.596^{* *}$ & 0.113 & 1.000 \\
\hline & Sig. (2-tailed) & 0.000 & 0.000 & 0.000 & 0.167 &. \\
\hline & $\mathrm{N}$ & 150 & 150 & 150 & 150 & 150 \\
\hline
\end{tabular}

Table-6: Correlations

** Correlation is significant at the 0.01 level (2-tailed).

${ }^{*}$ Correlation is significant at the 0.05 level (2-tailed).

The table above shows that the correlation is significant between Power and Prestige, Money attitudes and Distrust and Anxiety attitudes. Also, Retention-Time money attitudes correlate significantly with Distrust as well as Anxiety. The attitude Anxiety correlates with Distrust significantly as well.

\subsection{Relationship between Demographic Variables and Money Attitudes}

This section provides cross tabulations between various demographic variables and money attitudes.

\subsubsection{Cross Tabulations between Gender and Money Attitudes}

According to findings, females exhibited more Retention Attitude, while males exhibited more Power Prestige, more Distrust attitude, more Quality attitude and more Anxiety attitude as compared to others in the category.

The finding is depicted in the chart below that men are slightly high on Power and Prestige attitude compared to women but women comparatively are higher on TimeRetention attitude. Males are also higher on Quality attitude as compared to women. Although the chart shows differences among money attitudes and gender, these difference are not significantly different.

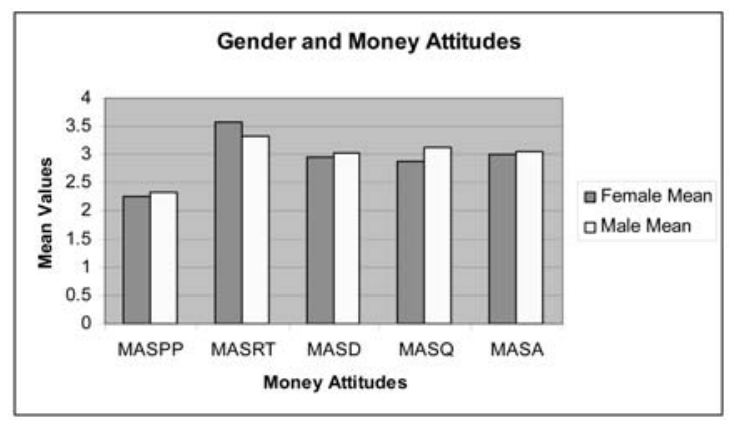




\subsubsection{Cross Tabulations between Age and Money Attitudes}

The data below shows the relationship of means of different items in age category with different money attitudes. According to data, 26-35 years of people exhibited more Power Prestige, 36-45 years of people show more Retention Attitude, 26-35 years of people exhibited more Distrust attitude, 55+ years of people exhibited more Quality attitude and 26-35 years of people exhibited more Anxiety attitude as compared to others in the category. Also, it is visible from this and other graphs that the highest scoring money attitude is that of Time-Retention, whereas the lowest is Power.

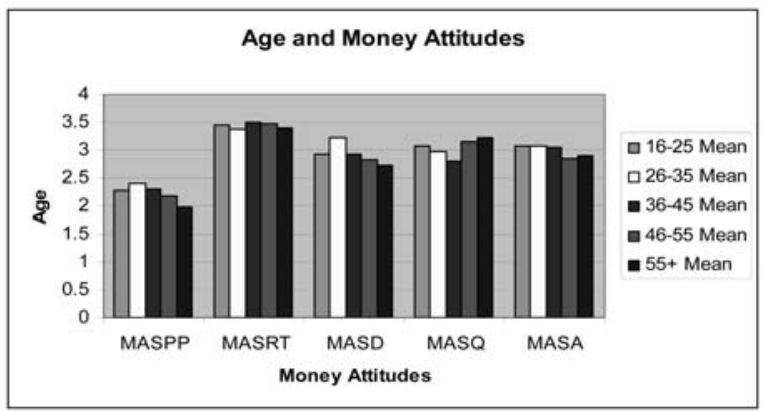

\subsubsection{Cross Tabulations between Income and Money Attitudes}

The findings show the relationship of means of different items in income category with the different money attitudes. According to the data, Rs.5, 000-25,000, people exhibited more power prestige, Rs. 25,000-50,000 people show more Retention Attitude, Rs.5, 000-25,000 people exhibited more Distrust attitude, Rs. 100,000-150,000 people exhibited more Quality attitude and less than Rs. 5,000 people exhibited more Anxiety attitude as compared to others in the category.

The chart below shows the relationship between Income and Money Attitudes clearly.

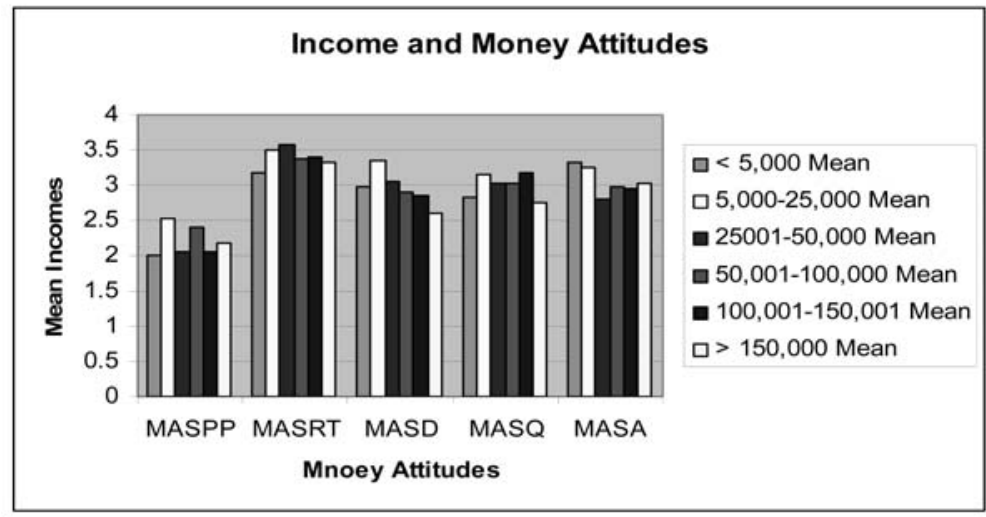




\subsubsection{Cross Tabulations between Marital Status and Money Attitudes}

The data shows the relationship of means of different items in marital status category with the different money attitudes. According to data, widowed people show more Retention Attitude and more Quality attitude. On the other hand, engaged people exhibited more power prestige, more Distrust attitude and more Anxiety attitude as compared to others in the category.

It is however important to note that the most relevant categories for us are married and single since there were a very few incidences of the other categories. Therefore, drawing conclusions on the 'other' categories on the basis of these averages would be misleading.

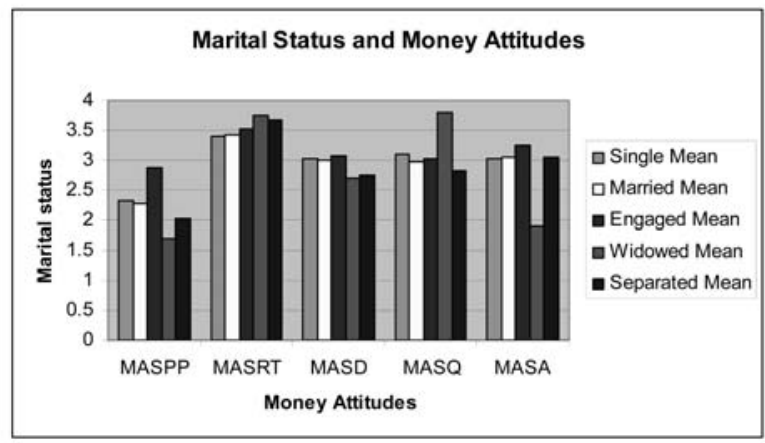

\subsubsection{Cross Tabulations between Education and Money Attitudes}

The data shows the relationship of means of different items in Education category with different money attitudes. According to data, uneducated people exhibited more power prestige, Retention Attitude, Distrust attitude and Anxiety attitude, whereas $\mathrm{PhD}$ people exhibited more Quality attitude as compared to others in the category.

The chart below shows that uneducated workers are higher on all attitudes except for quality whereas the more educated ones are lowest on Power and Prestige but high on retention and quality attitudes.

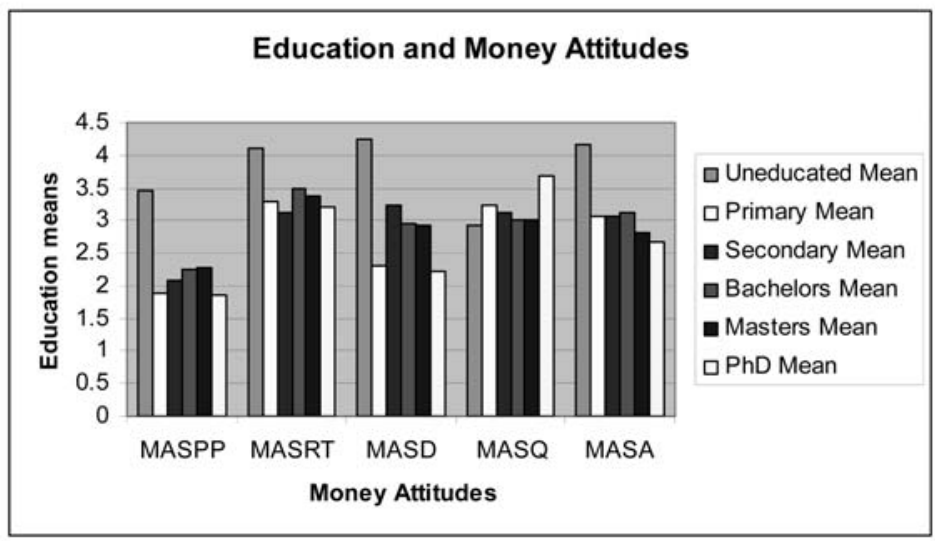




\subsection{Conclusion}

The objective of this study was to understand money attitudes of urban workforce of a developing country with respect to different demographic variables. The following were the key findings of the research:

i) The highest overall average for any money attitude is retention time. This means that majority of our urban workforce is more concerned about having enough money for the future. This could be due to various factors including economic uncertainty, social values and cultural dogmas. Quality and Anxiety attitudes are found to be close to the middle. Distrust and Power and Prestige scored low in the survey. This shows that the work force of Karachi does not attach a comparatively higher significance to money as a source of power and prestige nor does it consider money situations with suspicion and mistrust. However, historical understanding of Pakistani value systems and culture contradicts this finding greatly. One very important reason for this anomaly that the researcher has identified is that as far as Power and Prestige is concerned the MAS scale includes items that are so clearly negative that very few people provided their honest feedback upon it. For instance, two items on the scale were "Although I should judge the success of people by their deeds, I am more influenced by the amount of money they have" or "I behave as if money were the ultimate symbol of success." These and other such items have failed to generate truthful responses from respondents since these would put them in a highly negative light.

ii) One of the main findings of the study is that urban workforce of Karachi exhibit Power-Prestige and Retention other than neutral. However, Distrust, Quality and Anxiety were near to neutral. The research gives evidence regarding money attitudes and different demographic variables. It is apparent that retention attitude is high for females compared to males. In the all other four attitudes, males have scored higher but not that significantly. This leads us to believe that women compared to men are more concerned about saving and preparing for the future.

iii) Comparing money attitudes to age could not reveal any significant trend but some findings were; $26-35$ years of people exhibited more power prestige comparatively, 36-45 years of people show more Retention Attitude, 26-35 years of people exhibited more Distrust attitude and $55+$ years of people exhibited more Quality attitude.

iv) In comparing money attitudes with income, some findings were that people belonging to the lower income brackets exhibited more power prestige comparatively, whereas the middle income category reflected more retention and distrust attitudes. Also the upper class reflected more Quality attitudes and the lowest class (Rs. 5,000 or less) reflected anxiety attitudes. This is a compelling conclusion which automatically relates well with similar conclusions reached by Oleson (2004) and Engelberg and Sjoberg (2006) that money attitudes varied on the basis of need level as well as emotional intelligence; i.e the higher the need level and the emotional intelligence level, the lower importance will be given 
to money. If higher incomes can be taken to correlate with a higher emotional intelligence level as well as a self actualization level, we can conclude that this research finding supports the conclusions of other researchers.

v) Another interesting fact is that it is assumed that education plays a major role in developing money attitudes. But in this sample, except for Quality in all other factors, money attitude is the same for both highly educated people and those who are only primary educated. In all attitudes except for quality, the uneducated group scored the highest, which shows a high prevalence of status consciousness, distrust and anxiety about future income in the uneducated group. But this finding must be validated in future researches with application of statistical inference tests, as the proportion of low education and uneducated respondents in this sample were very small. Therefore, generalization cannot be made on this data alone.

\subsection{Recommendation}

- $\quad$ Future researches should be done to validate the findings of this research on a bigger sample as well as the application of inferential statistics techniques. This would allow data to be generalized on the population.

- Individuals can be classified in many different ways and demographics are the most basic form and often the starting point of these classifications. Future researches can explore into other classifications such as personal values, individual needs, family type, etc.

- $\quad$ Research can also be done to provide conclusive evidence in Pakistan as to when money attitudes are formed and how do they change over time. Lau (1998) and Furnham (1996) indicate that people form money attitudes at an early age and since from our research it is proved that education and money attitudes are dependent whereas age is not, then how are money attitudes formed at childhood and if they are not changing with age but education, then what is the interplay of these two variables, if any.

- $\quad$ Applied research can be done by Human Resource departments of firms to cater to people's money attitudes and improve their satisfaction at workplace. These attitudes, determined at smaller organizational level, can then be merged to develop a national/city wise/provincial scale and included in upcoming measures of a country's development and growth, such as gross national happiness (Bhutan) and Quality of Life and Happiness (France).

- $\quad$ Further research can be conducted in how these money attitudes can be defined into products. These products can then be positioned in a manner so as to satisfy money attitudes providing marketers with a new paradigm for branding and positioning. 


\section{References}

1 Begg, David, Fischer, Stanley and Dornbusch, Rudiger (1994) Economics, 4th Edition, McGraw Hill

2 Bonsu, S. (2007). "Ghanian attitudes towards money in consumer culture". International Journal of Consumer Studies, Vol. 32, pp. 171-178.

3 Burgess, S. M. (2005). "The importance and motivational content of money attitudes: South Africans with living standards similar to those in industrialized Western countries". South African Journal of Psychology, pp. 106-126.

4 Coutu, Diane (2003) "I was greedy too", Harvard Business Review, Vol. 81, No. 2, pp. 38-44

5 Davies, Glyn. (2002) A History of Money from Ancient Times to the Present Day, 3rd ed. Cardiff: University of Wales Press,

6 Furnham, A. (1996) 'Attitudinal correlates and demographic predictions of monetary beliefs and behaviors,' Journal of Organizational Behavior, Vol. 17, pp. 275-388.

7 Lau, S. (1998) 'Money: what it means to children and adults,' Social Behavior and Personality, pp. 297-306.

8 Macesich, George (2000) Issues in Money and Banking, Greenwood Press.

9 Oleson, M. (2004) 'Exploring relationship between money attitudes and Maslow's hierarchy of needs,' International Journal of Consumer Studies, pp. 83-92.

10 Orr, G. M. (2007) 'Measuring and Exploring Symbolic Money Meanings,' Psychology and Marketing, Vol. 24, No. 9, pp. 743-761.

11 Özgen, Ö., and Bayoglu, A. S. (2005) 'Turkish college students' attitudes towards money,' International Journal of Consumer Studies, Vol. 29, No. 6, pp. 493-501.

12 Engelberg, E. and Sjoberg, E. (2006) 'Money Attitudes and Emotional Intelligence,' Journal of Applied Social Psychology, Vol. 36, No.8, pp. 2027-2047.

13 Yamauchi, K. T., and Templer, D. I. (1982) 'The Development of a Money Attitude Scale,' Journal of Personality Assessment, pp. 522-528.

14 Yuon, Seounmi and Doyle, Kenneth (1999) 'Toward a cross-disciplinary dialogue about the meanings of money,' Advances in Consumer Research, Vol. 6, pp. 431-438. 